\title{
Factors affecting involvement of gender in childcare activities of agricultural labourers
}

\section{DIBYAPRAVA PRADHAN}

Received: 04.08.2014; Revised: 09.09.2014; Accepted: 23.09.2014

Author for correspondence: DIBYAPRAVA PRADHAN

Department of Human Development and Family Studies, College of Home Science, Orissa University of Agriculture and Technology, BHUBANESWAR (ODISHA) INDIA

Email: dibyapradhan@ rediffmail.com
ABSTRACT : Parental role and their involvement in childcare are very important for the overall development of the child. Here attempt has been made to quantify the percentage of involvement of both mother and father in childcare separately. Further to find out the correlation of parental involvement with different independent variables a study was conducted on 160 agricultural labourer households having at least one child in the age group of 1-5 years from 8 villages randomly selected from four blocks, which were purposively selected from four districts of Orissa. The percentage of share of fathers, mothers and other relatives in childcare was 19.92, 52.84 and 27.24, respectively indicating that mothers took care of their children more than two times than that of fathers and even members other than parents has more involvement than the fathers. The parental involvement was found to be positively correlated with their attitude, knowledge, skill and education whereas negatively correlated with number of children, family type and family size. Except family size, all the independent variables under the study were significantly correlated with parental involvement in case of both men and women. Regression analysis showed that the independent variables like attitude, skill, number of children and family type contributed significantly for the involvement of the women agricultural labourers in childcare.

KEY WORDS: Parental involvement, Childcare, Knowledge, Attitude, Skill, Education, Family size, Number of children

— HOW TO CITE THIS PAPER : Pradhan, Dibyaprava (2014). Factors affecting involvement of gender in childcare activities of agricultural labourers. Asian J. Home Sci., 9 (2) : 370-374. 